\title{
Major Species Production by Solid Fuels in a Two Layer Compartment Fire Environment
}

\author{
C. L. BEYLER \\ Division of Applied Science \\ Harvard University \\ Cambridge, Massachusetts 02138, USA
}

\section{ABSTRACT}

Major species production rates from burning polyethylene, poly(methyl methacrylate), and ponderosa pine were measured in a two layer compartment fire environment. Production rates were found to be correlated by the fuel to oxygen ratio, where the fuel supply rate is the fuel volatilization rate and the oxygen supply rate is the entrainment rate of oxygen between the fuel surface and the hot/cold layer interface. The results are similar to previous results with simple gaseous and evaporating liquids and support the observation that carbon monoxide production under fuel rich conditions is greater for oxygenated hydrocarbons than hydrocarbons.

Carbon monoxide yields for wood four times as large as the present results have been reported in the literature. These very large literature values were the result of sampling within the reaction zone. The present results and resenalysis of iterature results obviate the need to postulate three different thermal decomposition mechansims for wood at different fual to oxygen ratios as has been proposed in the literature.

An analysis of literature results indicates that under fuel rich conditions compartmenl residence times of 10-15 seconds are required for combustion to final products. Under fuel lean conditions far lower residence times are required, probably due to the enhanced mixing under these conditions.

\section{INTRODUCTION}

Investigations over the past twenty years have demonstrated that restricted ventilation can Increase the production of carbon monoxide by an order of magnitude or more[1-6]. This can have significant affects on the extent to which toxic products will cause other areas of the building to become untenable. A recent investigation[7] showed that the production rate of major chemical species per unit mass of fuel in a two layer environment can be expressed as a function of the fuel to oxygen ratio, where the fuel supply rate is the generation rate of fuel volatiles and the oxygen supply rate is the oxygen entrained into the flame between the fuel surface and the hot/cold layer interface. Fuels used in the investigation were gaseous and liquid fueis, and the correlations appeared insensitive to the thermo-fluidic details of the flame. The production of carbon monoxide under fuel rich conditions was found to be a strong function of the the fuel chemical structure with the results following the genaral ranking: axygenated hydrocarbons > hydrocarbons > aromatic hydrocarbons.

In this work the methods developed for determining the major chemical species production rates under restricted ventilation conditions in a two layer environment. using geseous and liquid fuels were used to study solid fuels of direct interest in fires in buildings. Experiments were performed using polyethylene, poly(methy) methacrylate), and ponderosa pine. Where evailable, the present results are compared with existing data.

\section{EXPERIMENTAL APPARATUS and PROCEDURES}

The apparatus used in these experiments included the hood system in which the hat gas layer was formed. the load cell system, and the gas sampling and analysis system. The hood system included the hood in which the

The present address for C. L. Beyler is Center for Firesafety Studies, Worcester Polytechnic Institute, Worcester MA 01609. 
hot gas layer was confined, the exhaust system, and instrumentation to control and measure the exhaust rate. The one meter diameter hood was constructed of sheet metal and the celling was made up of $0.012 \mathrm{~m}$ thick ceramic fiberboard backed by $0.025 \mathrm{~m}$ of ceramic fiberblanket. Fiberblanket $(0.025 \mathrm{~m})$ was also used to insulate the outer vertical surfaces of the hood. Gases were exhausted around the full periphery of the hood $0.3 \mathrm{~m}$ above the base of the $0.48 \mathrm{~m}$ daep hood through a vertical plenum system. The exhaust. was measured using a $0.044 \mathrm{~m}$ diameter orifice mater with flange taps in the $0.15 \mathrm{~m}$ exhaust duct. Temperature at the orifice meter was measured by thermocouple and the pressure drop was measured using an electronic manometer.

Specimen mass was measured using a water cooled LVDT load cell separated from the specimen by several layers of low density insulation. Mass loss rate was determined numerically and the average mass loss rato over the steady burning period was used in the analysis. The load call and specimen were positioned on the centerline of the hood and were mounted on a piston assembly to allow vertical positioning relative to the hood.

Hood exhaust gases were sampled at the orifice meter to insure a well mixed sample. Measurements of chemical composition at the hood exit indicated that no meaurable chemical reactions occurred in the exhaust system. Particulates were trapped immediately upon sampling and the sample gas was transported to the gas analyzers via $0.6 \mathrm{~cm} 0 . \mathrm{D}$. impolene tubing maintained at or above $70^{\circ} \mathrm{C}$.

The gas sample stream was analyzed using continuous analyzers for oxygen (polaragraphic,Beckman OM-11), carbon monoxide and dioxide (nondispersive IR absorption, infrared industries 702), total hydrocarbons(THC) (flame ionization detector(FID), $\mathrm{H}_{2} / \mathrm{He}$ carrier gas, Shimazdu), and water (dew point hygrometer, General Eastern 1200APS). Hydrogen was analyzed by gas chromatography. Flows to the oxygen, carbon monoxide/dioxide, and hydrogen analyzers were passed through a $-5^{\circ} \mathrm{C}$ cold trap and the resulting measurements were corrected for the volume of water removed(no correction for trapped hydrocarbons was made). Flows to the water and tolal hydrocarbon analyzers were maintained at or above $70^{\circ} \mathrm{C}$ and no corrections were required. The total hydrocarbon dats was interpreted as $\mathrm{CH}_{2}$. An H/C ratio of two was assumed in order to represent general hydrocarbons.

The operation of the apparatus involved three basic parameters which were controlled by the experimenter: the vertical position of the specimen, the specimen surface area, and the hood exhaust rate. Generally, the last two were chosen and the vertical position of the specimen was set so that the layer/air interface was below the exhaust lip and above the base of the hood. The layer interface was maintained $10-15 \mathrm{~cm}$ above the base of the hood. In this way all gases leaving the layer were contained in the exhaust flow and no additional ambient gases were contained in the exhaust. flow.

Experiments were performed using $0.025 \mathrm{~m}$ thick low density polyethyleng(LDPE) in $0.2,0.23,0.255 \mathrm{~m}$ diameter pans. After ignition the polyothylene burned slowly until the whole specimen had melted. The burning rate then increased to a steady rate. Poly(methyl methacrylato) (PMMA) wos oblained as $0.025 \mathrm{~m}$ thick slab stock and was burned with fuel surface areas of $0.023-0.061 \mathrm{~m}^{2}$. Ponderosa pine was burned in cribs designed to be fuel surface controlled in open burning. Each of the three to five layers was made up of three, $0.036 \mathrm{~m}$ thick, $0.2 \mathrm{~m}$ long sticks. All fuels were ignited using a propane torch.

\section{CORRELATION CONCEPTS}

The mass production rate of a species i per unit mass of fuel volatilized is known as the mass $y$ ield, $Y_{j}$. If the chemical composition of the fuel volatiles is known, the yield can be normalized by the maximum possible mass production rate of species $i$ per unit mass of fuel volatiles, $k$. This is known as the normalized yield of species $i$. $f_{i}$. As the chemical composition of the fuel volatiles is not generally known for solid fuels, especially those that

\begin{tabular}{|c|c|c|c|c|c|}
\hline Fuel & Empirical Formula & $\begin{array}{l}(F / 0)_{\text {stoich }} \\
\text { (mass units) }\end{array}$ & $k_{O 2}$ & $\begin{array}{l}{ }^{k}(02 \\
\text { units }\end{array}$ & $k_{\mathrm{H} 2 \mathrm{O}}$ \\
\hline PE & $\mathrm{CH}_{2}$ & 0.29 & 3.43 & 3.14 & 1.28 \\
\hline $\begin{array}{l}\text { PMMA } \\
\text { Pine }\end{array}$ & $\mathrm{C}_{0}^{\mathrm{C}_{5} \mathrm{H}_{8} \mathrm{H}_{2}^{2} \mathrm{O}_{2}{ }^{(\mathrm{a})}}$ & $\begin{array}{l}0.52 \\
0.83\end{array}$ & $\begin{array}{l}1.92 \\
1.13\end{array}$ & $\begin{array}{l}2.20 \\
1.40\end{array}$ & $\begin{array}{l}0.72 \\
0.72\end{array}$ \\
\hline
\end{tabular}



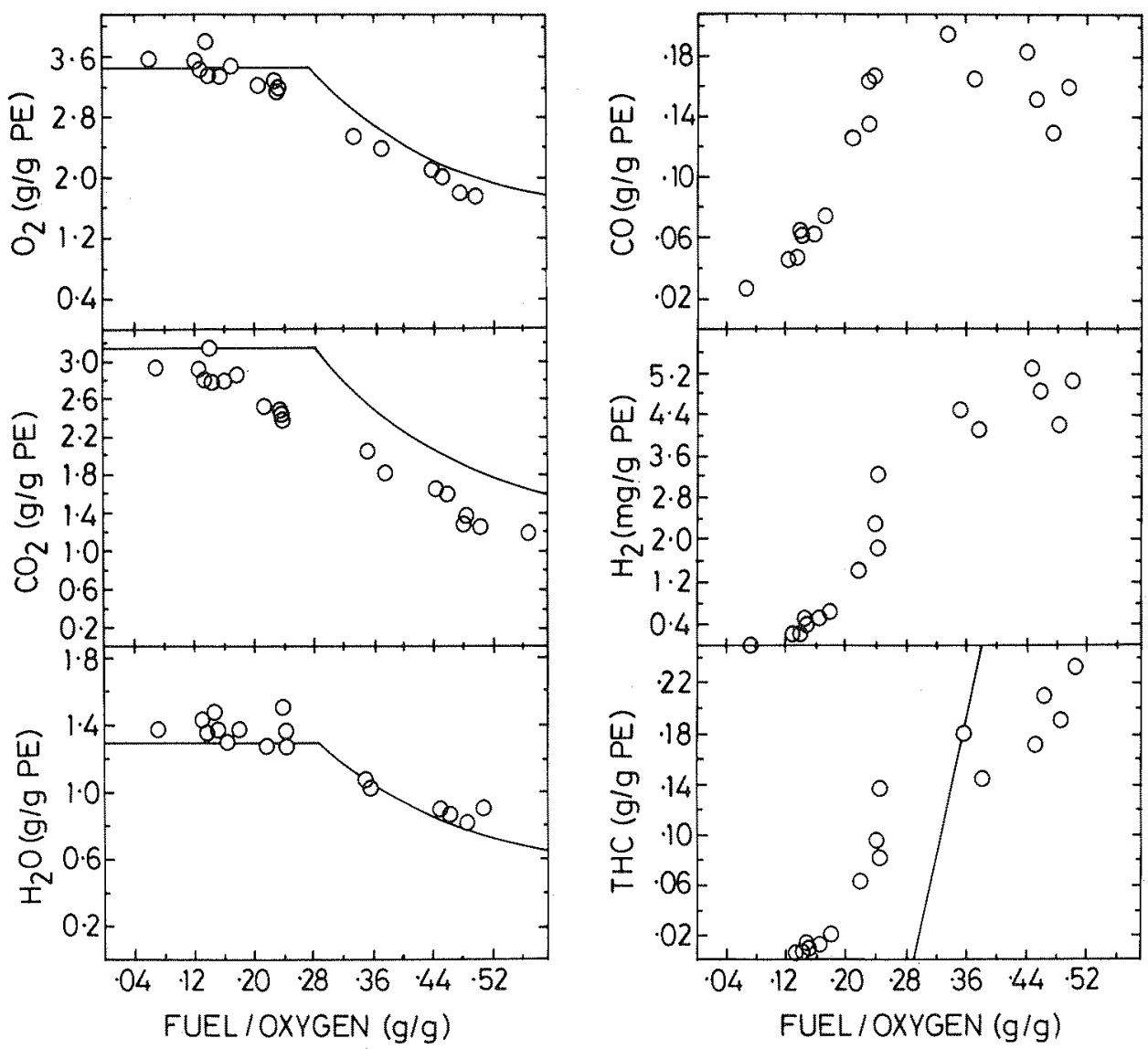

rigure 1. Mass yield of major species for polyothylene as a function of the mass fuel to oxygen ratio. Solid lines are the prediction of Equation 1 using constants in Table 1.

char, the present results will be presented in terms of mass yialds. The yield of oxygen refors to the consumption rather than the production of oxygen.

In two layer compartment fire environments the chemical species yields will be a function of the mass fuel to oxygen ratio. ( $F / 0$ ). where the fuel supply rate is the fuel volatilization rate and the oxygen supply rate is the rate of oxygen entrainment between the fuel surface and the hot/cold layer interface. This can be normalized by the stoichiometric fuel to oxyegn ratio, $(\mathrm{F} / \mathrm{O})_{\text {stoich }}$ if the chemical composition of the fuel volatiles is known. This normalized fuel to air ratio is known as the equivalence ratio, 0 . The equivalence ratio is the reciprocal of the stoichiometric fraction used by Tewarson[5,9].

The simplest possible model for combustion of $\mathrm{C}, \mathrm{H}, \mathrm{O}$ containing fuel is given by

$\mathrm{F}+\mathrm{O}_{2} \rightarrow$ products + excess oxygen

for $\emptyset<1$

$\mathrm{F}+\mathrm{O}_{2} \rightarrow$ products + excess fusl

for 0,1

where the products are carbon dioxide and water. Taking excess fual as total hydrocarbon, the following 

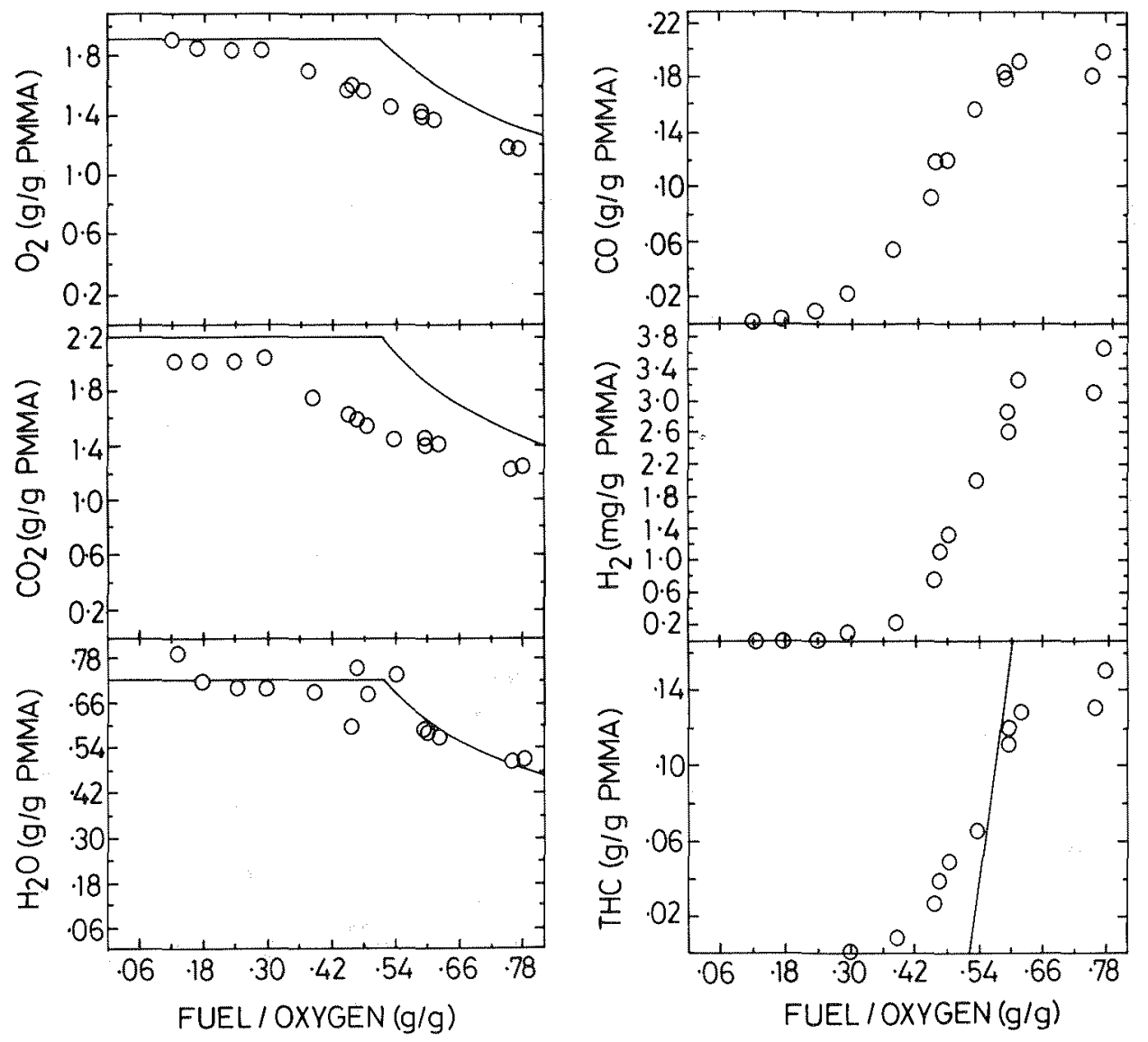

Figure 2. Mass yleld of major species for poly(methyl methacrylate) as a function of the mass fuel to oxygen ratio. Solid lines are the prediction of Equation I using constants in Table 1.

normalized yield expressions result

$$
\begin{array}{ll}
f_{C O 2}=f_{H 2 O}=f_{O 2}=1, f_{T H C}=0 & \text { for } \emptyset_{<1} \\
f_{C O 2}=f_{H 2 O}=f_{O 2}=1 / \emptyset . f_{T H C}=1-1 / \emptyset & \text { for } \emptyset>1
\end{array}
$$

These relationships provide a good first estimate of the production rate of carbon diaxide, water. total hydrocarbons, and consumption of oxygen. To within the approximation that the heat of reaction of oxygen is constant, the oxygen normalized yield is also the combustion efficiency.

\section{RESULTS AND DISCUSSION}

Major species results for low density polyethylene, poly(methyl methacrylate), and ponderosa pine are shown in Figures 1-3. The yield relations of Equation 1 are also plotted using constants given in Table 1 . The constants for polyethylene and poly(methyl methacrylate) are those for pure polymer. The constants chosen for 1 

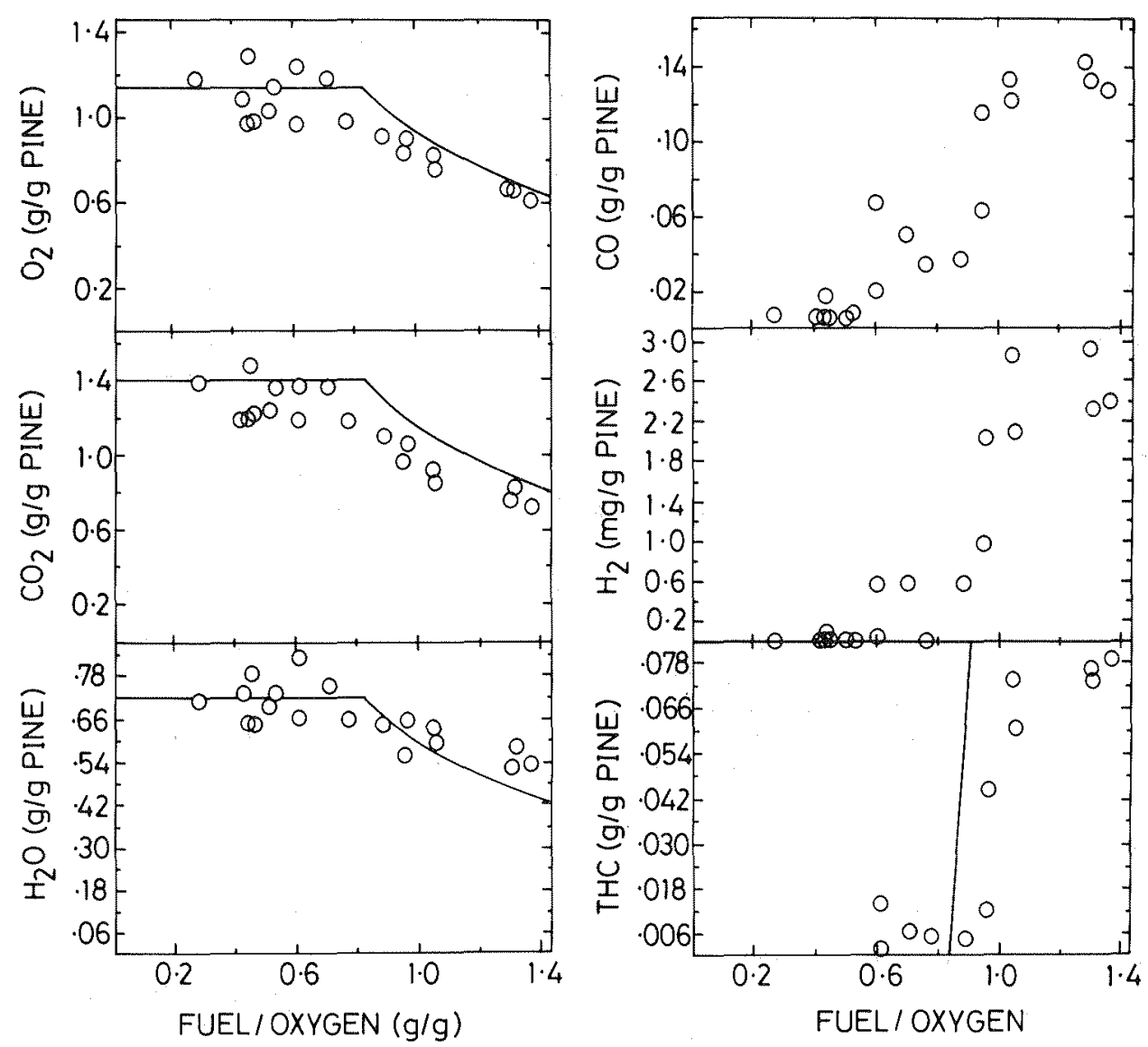

Figure 3. Mass yield of major species for ponderosa pine as anction of the mass fuel to oxygen ratio. Solid lines are the prediction of Equation 1 using constants in Table 1.

pine volatiles were determined from the low fuel to oxygen ratio yields of carbon dloxide, water, and oxygen. The empirical chemical formula chosen was that formula which reasonably represented all three yields simultaneously. but no formal fitting procedure was employed.

The results for all three solid fuels exhibit the same qualliative features previously observed with gaseous and liquid fuels. In particular the carbon dioxide, water, and oxygen generally follow the simple relations of Equation 1 with carbon dioxide deviating to an extent consistent with the production of carbon monoxide and soot. As previously observed for other fuels. the water yield remains at the low equivalence ratio yield quite near the stoichiometric fuel to oxygen ratio. In general the total hydrocarbon yields at high fuel to oxygen ratlos are less than expected on the basis of Equation 1. For oxygenated fuels this has proviously been observed and is due to the reduced response of flame ionization detectors to oxygenated hydrocabons[7]. Further. using $\mathrm{CH}_{2}$ as a formula for axygenated hydrocarbons also underestimates the mass production rate. However, the total hydrocarbon yields at high fuel to oxygen ratios for polyethylene are lower than expected on the basis of previous work. This may result from condensation of high molecular weight oligomeric products of thermal decomposition of polyethylene. 
TABLE 2. Summary of results

\begin{tabular}{|c|c|c|c|c|c|c|}
\hline \multirow{3}{*}{ Fuel } & \multirow{3}{*}{$\begin{array}{l}\text { Empirical } \\
\text { Formula }\end{array}$} & \multirow{2}{*}{$\begin{array}{c}0<0.7 \\
\text { Normalized }\end{array}$} & \multicolumn{4}{|c|}{1.2} \\
\hline & & & \multicolumn{2}{|c|}{ Vol.Pct. } & \multicolumn{2}{|c|}{ Normalized Yields } \\
\hline & & $\mathrm{CO}_{2}$ Yiald & $\mathrm{RO}_{2}$ & $8 \mathrm{co}$ & $\mathrm{CO}$ & $\mathrm{H}_{2}$ \\
\hline Propans & & 0.95 & 0.5 & 1.8 & 0.12 & 0.06 \\
\hline Propene & $c_{3}$ & 0.68 & 2.0 & 1.6 & 0.10 & 0.03 \\
\hline Hexanes & & 0.93 & 3.0 & 1.6 & 0.10 & 0.03 \\
\hline Toluene & & 0.78 & 8.0 & 0.7 & 0.05 & 0.01 \\
\hline Methanol & $\mathrm{CH}_{3} \mathrm{OH}$ & 0.96 & 0.1 & 4.8 & 0.27 & 0.10 \\
\hline Ethanol & $\mathrm{C}_{2} \mathrm{H}_{5} \mathrm{OH}$ & 0.97 & 0.1 & 3.6 & 0.18 & 0.075 \\
\hline Isopropanol & $\mathrm{C}_{3} \mathrm{H}_{7} \mathrm{OH}$ & 0.96 & 2.0 & 2.4 & 0.12 & 0.05 \\
\hline Acetone & $\mathrm{C}_{3} \mathrm{H}_{6} \mathrm{O}$ & 0.94 & 0.7 & 4.4 & 0.21 & 0.045 \\
\hline PE & $\mathrm{CH}_{2}{ }^{\circ}$ & 0.91 & 2.0 & 1.7 & 0.09 & 0.035 \\
\hline PMMA & $\mathrm{C}_{5} \mathrm{H}_{8} \mathrm{O}_{2}$ & 0.91 & 2.0 & 3.0 & 0.135 & 0.04 \\
\hline Pine & $\mathrm{C}_{0} 05 \mathrm{H}_{2} 4^{\mathrm{O}}$ & 0.93 & 2.0 & 3.2 & 0.155 & 0.03 \\
\hline Methane(a) & $\mathrm{CH}_{4}$ &.-- & $\ldots$ & 1.6 & 0.10 & $\ldots$ \\
\hline
\end{tabular}

(a) calculated fron the data of Cetegen,B.M., Zukoski,E.E., Kubota,T., NBS-GCR-82-402.

The results of the present solid fuel data and previous gas and liquid fuel data are summarized in Table 2.The present data are consistent with the previous observation of higher normalized carbon monoxide yields for axygenated hydrocarbon fueis than hydrocarbon fuels. However. the carbon monoxide yleid for ponderosa pine is less than expected based on its high $0 / C$ ratio. This probably results from the high water content of the volatiles which contributes to the $\mathrm{O} / \mathrm{C}$ ratio, but does not contribute to carbon monoxide production. While some relation exists between $\mathrm{O} / \mathrm{C}$ and $\mathrm{H} / \mathrm{C}$ ratios and carbon monoxide yields, the chemical structure of the fuel volatiles must be considered in order to explain the carben monoxide yielós observed.

\section{COMPARISON WITH COMPARTMENT FIRE DATA}

of the fuels used in the present investigation. compartment fire data including fuel mass loss rate and species concentration measurements appear to exist only for wood. Tewarson[9] has recently reviewed and analyzed the existing wood data. His analysis led him to the conclusion that at least three mechenisms of thermal decomposition were required to explain the mass yield of carbon monoxide as a function of the equivalence ratio. His analysis of the data led to calculated carbon monoxide yields of up to $0.6 \mathrm{gms} / \mathrm{gm}$ of fuel volatilized, over four times the maximum observed in this study. Vields of this magnitude were principally deduced from the small scale compartment fire data of Gross and Robertson[1], Tewarson[3], and Croce[6]. In these investigations the species measurements were made inside the compartment with uncooled probes.

The analysis of Tewarson[9] was based on several assumptions which may not have been satisfied. The most significant in terms of the present discussion is the assumption that the composition measurements made in the compertment were representative of the products of combustion. In their paper Gross and Robertson[ I] indicated that errors in species concentration measurements resulted from the use of an uncooled probe. The magnitude of the errors incurred is best illustrated by an example presented by Gross and Robertson themseives[10]. In the same experiment both a water cooled and an uncooled probe were used for sampling at approximately the same location in the compartment. The uncooled probe measured $4.1 \% \mathrm{CO}, 7.4 \% \mathrm{CO}_{2}$, and 12.8\% $\mathrm{O}_{2}$, while the cooled probe measured $1.2 \% \mathrm{CO}_{1}, 1.5 \% \mathrm{CO}_{2}$, and $20.4 \% \mathrm{O}_{2}$ (all measured on a dry basis). Clearly, the sample was drawn from a region of chemical reaction and the reaction continued within the uncooled probe.

If we assume that the sample drawn from the compartment is likely to be drawn from the reaction zone if the flame volume is large, plot of the mass carbon monoxide yield as function of the ratio of the flame volume to the enclosure volume may indicate in which experiments the chemical sampling was done incorrectly for the present purposes. While no measurements of flame volume were made, an estimate can be made by assuming the heat release per unit volume is the same as Orloff and deRis [11] found in the open, $1200 \mathrm{~kW} / \mathrm{m}^{3}$. Using the measured mass loss rate and an estimated heat of combustion for wood volatiles of $15 \mathrm{~kJ} / \mathrm{g}[12]$, such a plot for Gross and Robertson's small enclosure data is shown in Figure 4 . All the data with mass carbon 


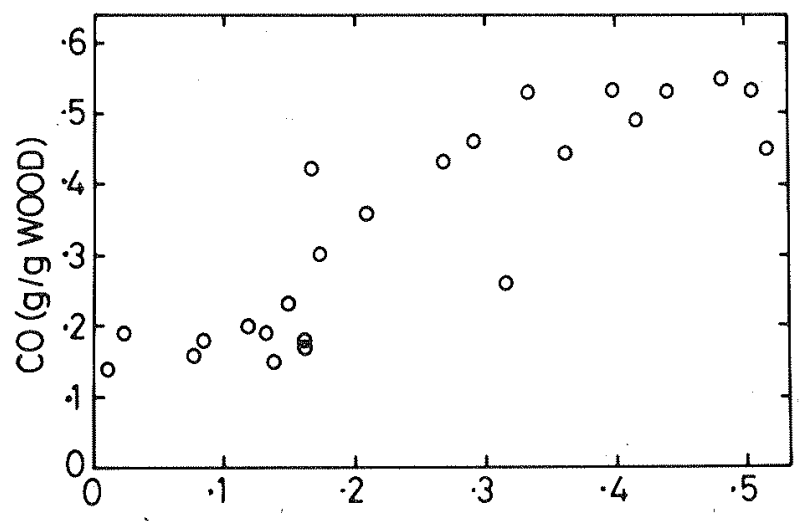

\section{FLAME VOLUME / ENCLOSURE VOLUME}

Figure 4. Mass carbon monoxide yields calculated by Tewarson[9] from the small scale enclosure data of Gross and Robertson[1] plotted as a function of the ratio of the estimated flame volume to the enclosure volume.

monoxide yields greater than 0.25 result from experiments in which the flame volume estimate is greater than $16.5 \%$ of the enclosure volume. Figure 5 is a plot of the existing wood compartment fire data as analyzed by Tewarson with the data with estimated flame volumes greater than $16.5 \%$ of the compartment volume indicated as solid symbols. In analyzing the data Towarson used a $k_{02}$ for the original wood and applied it to the wood volatiles. As a result stoichiometric conditions correspond to a stoichiomatric fraction of 0.7 rather than the expected 1.0. Figures 4 and 5 show that the very large carbon monoxide yields deduced resulted from incorrect ges sampling.

The present attempt to identify inappropriate data is an after the fact analysis based on incomplete information and may not be sufficiently severe. Even where the chemical composition was not measured in the reaction zone, it may not be a representative sample of the exhaust gases due to unmixedness. It is also of note that the carbon monoxide yields from the compartment data are approximately $20 \%$ overestimated due to the lack

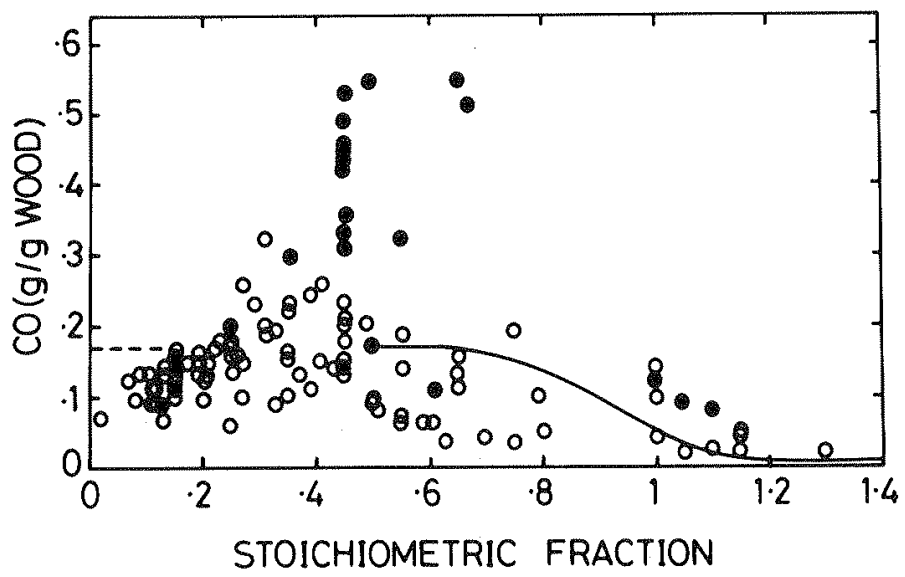

Figure 5. Mass carbon monoxide yields calculated by Tewarson[9] from data in References 1,3 and 6 . Filled symbols indicate data which were sampled from the reaction zone based on the criterion that the estimated flame volume was greater than $16.5 \%$ of the enclosure volume. The solid line is the present results with the water correction removed and the dashed line is the oxidative pyrolysis data of Tewarson[9]. 
of a correction for water removed from the sampled gases before analysis. Finally, the exhaust rate from the compartment was not measured in any of the original studies but was inferred by Tewarson by requiring that the carbon dioxide and oxygen yields as a function of equivalence ratio in the compatment fire studies match that determined in Tewarson's flammability apparatus and some duct fire tests at the Bureau of Mines. While this is a plausible essumption, it clearly introduces uncertainty into the correlation of Figure 5.

In the light of the the present data and the limitations of the compartment fire correlations of Tewarson, it is clear that Tewarson's postulate of changes in the thermal decomposition of wood as a function of the fuel to oxygen ratio is not required to explain the mass carbon monoxide yield as a function of the fuel to oxygen ratio. The carbon monoxide yield as a function of the fuel to oxygen ratio is qualitiatively similar to that observed for simple evaporating liquids and gaseous fuels.

While the measurements from within the reaction zone made in the work of Gross and Robertsonl11. Tewarson [3], and Croce[6] were made with uncooled probes, it is nonetheless interesting to examine the relationship between the carbon monoxide yield and the residence time of the gases in the compartment. Takeda and Akita [ 13 ] have proposed that reductions in heat release within a compartment due to unmixedness of fuel and oxygen may be described by a combustion efficiency, $\mu$, given by

$\mu=1-\exp \left(-t_{\text {res }} / t_{\text {mix }}\right)$

where $t_{\text {res }}$ is a residence time, and $t_{\text {mix }}$ is a required mixing time for combustion. Motivated by this stirred reactor type expression, it is proposed that the effect of limited residence time in the compartment on carbon monoxide yleld can be expressed as

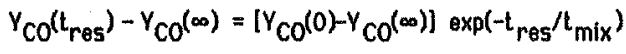

where $Y_{C O}{ }^{(\infty)}$ is the carbon monoxide yield uneffected by limited residence time, $t_{\text {res }}$ is the residence time given by the volume of the enclosure divided by the volume exhasut rate, and $t_{m i x}$ is a yet to be defined mixing time. As all of Gross and Robertson's data[ [1] in their small compartment are in the fuel rich regime where a constant $Y_{C O}\left({ }^{\infty}\right)$ is anticipated on the basis of all fuels examined to date. these data present a particularly simple system with which to test Equation 2. The pine results of the present imvestigation indicate that $Y_{C O}(\infty)=0.14$. If we remove the water correction from the present results to be consistent with Gross and Roberston's data, $Y_{C O}{ }^{(\infty)}$ is increased to 0.17 . Figure 6 shows a plot of $\ln \left(Y_{c o}{ }^{(t r e s)-0.17)}\right.$ as a function of the residence time for Gross and

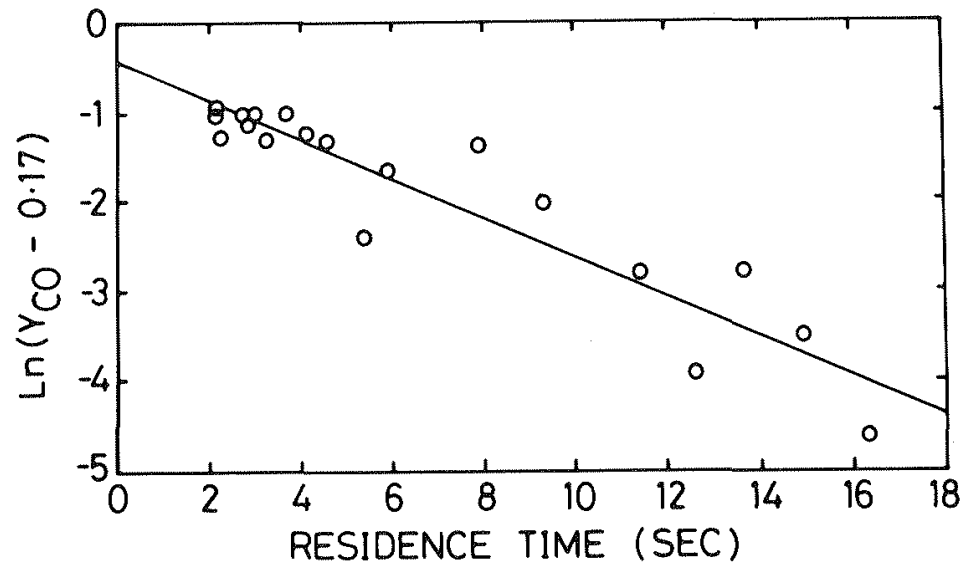

Figure 6. Evaluation of Equation 2 as a model of the effect of residence time on mass carbon monoxide yielós using the small scale data of Gross and Robertson[ 1]. The slope of the plotted line is consistent with $t_{\text {mix }}=4.5$ seconds. Robertson's small enclosure data with residence times less than 18 seconds. Data with larger residence times were excluded as the choice of $\left.Y_{C O}{ }^{(\infty)}\right)$ dominates tha behavior of the plot for large residence times. The slope of this plot is consistent with $\mathrm{I}_{\mathrm{mix}}=4.5$ seconds. 
While the definition of the residence time used here is different than that used by Takeda and Akita, Figure 6 is direct chemical evidence of the effect of residence time on chemical species yields. The determined mixing time of 4.5 seconds should be considered as indicative of the order of magnitude of the required mixing time, rather than a quantitative determination, given the assumptions required for fts determination and the quality of the original data.

It is of interest to note that all the fuel rich carbon monoxide yields determined from the data of References 1,3, and 6 are correlated by a plot of carbon monoxide yield as a function of the residence time. However, under fuel lean conditions the carbon monoxide yields show no correlation with residence time. Further, for fuel rich conditions the requirement that the flame volume be less than $16.5 \%$ of the enclosure volume is essentially equivalent to requiring the residence time to be greater than $7.5 \mathrm{~seconds}$. For fuel lean conditions, requiring a residence time greater than 7.5 seconds excludes data which is not rejected by the volume ratio requirement of 16.5\%. This indicates that the effect of residence time on product yields and combustion efficiency is different under fuel lean and fuel rich conditions. This result is not in accordance with the model of Takeda and Akita, but must be regarded as somewhat speculative given the quality of the data in References 1.3, and 6 for present purposes. It is significant to note that. Takeda and Akita presented no chemical evidence for their madel. Rather, they depended upon the results of calculations of the volatilization rate using a model incorporating their combustion efficiency expression to validate their model.

The force responsible for mixing in the hot layer is characterized by the momentum of the plume now as is enters the hot layer, if all the momentum of the plume flow is dissipated within the compartment. The intensity of mixing processes in the layer under geometrically similer conditions is expected to be proportional to the ratio of the momentum flux to the mass flux as the flame enters the layer the ratio of the force dissipated to the mass of gases involved). This ratio is simply the mass averaged fame gas velocity. According to the data and analysis of Cox and Chitty [14], the mass averaged veolcity increases as $2^{1 / 2}$ in the continuous flaming region of open fiames and becomes constent in the intermittent region. Under fuel rich conditions the layer interface is always in the continuously flaming region of the flame. As the required mixing time is expected to vary inversely with the mixing intensity, this indicates that the required mixing time will be greatest under fuel rich conditions. Both the required mixing time and the fraction of fuel not burned in the plume will decrease as the fuel to oxygen ratio decreases.

The $Z^{1 / 2}$ dependence of the mass averaged velocily also indicates that the required mixing time may decrease with increasing compartment scale under fuel rich conditions. However, fuel source size effects were not included in the analysis [14] and such effects may have equally strong scale effects. Scale effects cannot be examined using existing data as there are virtually no fuel rich, low residence time data available at large scale. This strong bias of low residence times for small compartments results from the use of very large cribs in small compartments to increase the steady burning period. The small scale data of Crocel6] suffers least from this tendency due to the use of Froude modeling concepts in experiment scaling.

For the purposes of toxic products production and transport, restricted compartment residence time results are not of direct relevance, as reaction will continue outside the compartment in regions which will be untenable on a thermai basis alone. That is to sey a flame will extend from the the compartment vent under these conditions.

The efficiency of the external flame in destroying toxic products then becomes a relevant consideration. If the air used for this combustion is unvitiated, it may be reasonable to expect the combustion to be essentially as efficient as burning in the open. However, this remains to be shown.

\section{CONCLUSIONS}

Major species production rates measured for polyethylene, poly(methyl methacrylate), and ponderosa pine as a function of the fuel to okygen ratio are qualitiatively similar to that proviously measured for simple gaseous and evaporating liquid fuels. The normalized carbon monoxide yield results support the observation that oxygenated hydrocarbons produce carbon monoxide more efficiently than hydrocarbons under fuel rich conditions.

It is not necessary to postulate multiple thermal decomposition mechanisms to explain the carbon monoxide yield of wood as suggested by Tewarson[9]. The carbon monoxide yield is qualitativoly similar to simple gaseous and evaporating liquid fuels. Provious measurements indicating carbon monoxide yields as much as four times greater than the present data were the result of sampling within the reaction zone. Such measurements can not be used directly in the prediction of the production and spread of toxic products within a building. 
Analysis of existing wood crib compartment fire data indicates that compartment residence times of 10-15 seconds are required for reaction to final products under fuel rich conditions. Under fual lean conditions far shorter residence times appear to be required, indicating more intense mixing under these conditions.

\section{REFERENCES}

1. Gross,D., Robertson, A.F., Tenth Symposium(International) on Combustion. The Combustion institute, Plttsburgh, Pa.(1965), 931.

2. Rasbash,D., Stark, W. The Generation of Carbon Monoxide by Fires in Compartments, Fire Research Note 614 , Fire Research Station, Borehamwood, England, 1966.

3. Tewarson,A., Combustion and Flame, 19, (1972) 101.

4. Tewarson,A., Combustion and Flame, 19. (1972) 363.

5. Tewarson,A., Steciak, J., Comb. and Flame, 53, (1983) 123.

6. Croce, P., Modeling of Vented Enclosure Fires Part 1, Cuasi-sleady Wood Crib Source Fire, Factory Mutual Research Corp.. Technical Report FMRC J.I. 7AOR5.6U, July 1978.

7. Beyler,C.L., accepted for publication, Fire Safoty Journal , 1985.

8. Beyler, C.L., Development and Burning or a Laver or Products of incomplete Combustion Generated by Buoysent Diffusion Flame, Ph.D. Thesis, Harvard University, 1983.

9. Tewarson, Twentioth symposium(International) on Combustion. The Combustion Institule, PIttsburgh, Pa. (1985).

10. Gross,D., Robertson,A.F., NBS Report 8147, National Bureau of Standards, Washington D.C., 1964.

11. Orloff, L., deRis, J., Nineteenth symposium(international) on Combustion. The Combustion Institute. Pittsburgh, Pa. (1982), 885.

12. Atrsya,A., Pyrolysis, Ignition, and Fire Spread on Horizontal Surfaces of Wood, Ph.0. Thesis, Harvard University, 1983.

13. Takede,H., Akita,K., Nineteenth Symposium(International) on Combustion. The Combustion Institute. Pittsburgh, $\mathrm{P}_{\mathrm{a} .}$ (1982), 897.

14. Cox,6.z Chitty.R., Combustion and Flame, 39, (1980) 191.

\section{ACKNOWLEDEEMENTS}

The author would like to thank Prof. Howerd Emmons for his guidance through the course of this work. This research was supported by the United States Department of Commerce, National Bureau of Standards, Grant No. 6ONANB 400010. 